\title{
Removal of Mefenamic Acid from Aqueous Solution by Fenton Process: Optimization Using Response Surface Methodology with Central Composite Design
}

\author{
R. Deepa*, G. Madhu*†, Roy M Thomas* and V. Sivanandan Achari** \\ *School of Engineering, Cochin University of Science and Technology, Kochi-682 022, Kerala, India \\ **School of Environmental Studies, Cochin University of Science and Technology, Kochi-682 022, Kerala, India \\ $\dagger$ Corresponding author: G. Madhu; profmadhugopal@gmail.com
}

Nat. Env. \& Poll. Tech.

Website: www.neptjournal.com

Received: 07-05-2021

Revised: 25-06-2021

Accepted: 01-07-2021

Key Words:

Mefenamic acid

Fenton process

Hydroxyl radical

Response surface methodology

\section{ABSTRACT}

In the present study, the three main process parameters in the Fenton process for the removal of pharmaceutical compound Mefenamic acid from an aqueous solution were optimized using response surface methodology (RSM). Central composite design (CCD) was used for process optimization. The primary and secondary interaction effects of the selected parameters such as $\mathrm{H}_{2} \mathrm{O}_{2}, \mathrm{Fe}^{2+}$ and $\mathrm{pH}$ on the removal of mefenamic acid were examined. A mathematical model for the removal process based on the selected variables was developed. The interaction effect between the chosen parameters shows that the removal of mefenamic acid was enhanced in the acidic $\mathrm{pH}$ range at a high concentration of $\mathrm{H}_{2} \mathrm{O}_{2}$ and in a medium concentration level of the catalyst $\mathrm{Fe}^{2+}$. The removal efficiency of $81.24 \%$ was obtained for mefenamic acid at the optimized condition of variables such as $9.36 \mathrm{mM} \mathrm{H}_{2} \mathrm{O}_{2}, 0.058 \mathrm{mM}$ $\mathrm{Fe}^{2+}$ and at a $\mathrm{pH}$ value of 2.1 .

\section{INTRODUCTION}

Pharmaceuticals compounds are one of the emerging contaminants, the presence of which even in trace levels in water sources can cause lethal effects on human beings and aquatic organisms. By the development of modern analytical techniques, various categories of pharmaceutical compounds such as analgesics/anti-inflammatory, $\beta$-blockers, psychiatric drugs, antibiotics, lipid regulators, contrast agents, anti-cancer agents, and hormones have been identified in municipal and hospital wastewaters and even in surface and groundwater sources (Wang et al. 2014, Bu et al. 2016). To remove these non-biodegradable and persistent compounds, in addition to the conventional treatment methods, various advanced treatment techniques such as adsorption, reverse osmosis, microfiltration, advanced oxidation, and nano filtration techniques are under research (Rivera-Utrilla et al. 2013).

Among the advanced treatment techniques, advanced oxidation processes (AOPs) are found to be promising. AOPs are based on the formation of highly reactive and non-selective oxidants such as hydroxyl radical $(\bullet \mathrm{OH})$, superoxide radical $\left(\bullet \mathrm{O}_{2}\right)$, hydroperoxyl radicals $\left(\bullet \mathrm{HO}_{2}\right)$, sulfate radicals $\left(\bullet \mathrm{SO}_{4}{ }^{-}\right)$ and peroxyl radical $(\bullet \mathrm{ROO})$ generated under atmospheric or subcritical conditions of temperature and pressure, with or without catalyst and/or energy. These oxidants degrade the persistent organic compounds into carbon dioxide and water or convert them into metabolite forms (Deng \& Zhao 2015). There are several types of AOPs based on the techniques used for the in situ formation of oxidant radicals such as chemical, photochemical, sonochemical, microwave-assisted, and electrochemical AOPs (Andreozzi et al. 1999). Fenton process is a chemical AOP method in which $\bullet \mathrm{OH}$ radicals are produced by the catalytic decomposition of $\mathrm{H}_{2} \mathrm{O}_{2}$ by iron salts in an acidic medium (Oturan \& Aaron 2014). The advantage of this process is its simple operation principle, environmentally safe nature, short reaction time, and the absence of mass transfer limitation (Naveed et al. 2017). The removal efficiency of the Fenton process depends on various factors such as initial $\mathrm{pH}$, reaction time, initial pollutant concentration, the dosage of Fenton reagent, reagent mole ratio, mode of addition of $\mathrm{H}_{2} \mathrm{O}_{2}$, and temperature (Roudi et al.2018).

Mefenamic acid (MEF) is a nonsteroidal analgesic and anti-inflammatory drug (NSAID). It is commonly used to reduce pain, menstrual pain, dysmenorrhea, migraine and is also used in the treatment of rheumatoid arthritis and other muscular-skeletal diseases (Idrees 2015). In European Union (EU), mefenamic acid is considered a third-class priority pollutant as its concentration in various environmental compartments has been detected larger than the no-effect concen- 
tration value of $0.428 \mu \mathrm{g} . \mathrm{L}^{-1}$ (Chang et al.2012). The removal of mefenamic acid by photolysis, adsorption on activated carbon, and ozonation showed that $60 \%$ removal efficiency in 120 min was achieved by applying a combination of UV and ozone. Also, it reveals that the activated carbon addition did not enhance the removal of the compound (Gimeno et al. 2010). Nitrite-induced photo transformation studies of MEF showed that intermediate photo transformation products are formed and they were found more toxic than mefenamic acid (Chen et al. 2016). Different oxidative processes such as UV, $\mathrm{UV} / \mathrm{H}_{2} \mathrm{O}_{2}$, Fenton, and photo Fenton were investigated and optimized using fractional factorial design and found photo Fenton process using ferric oxalate and hydrogen peroxide at a $\mathrm{pH}$ of 6.1 gives a maximum removal of $95.95 \%$ in 60 min (Colombo et al. 2016).

Polyurea formaldehyde-Bentonite was tested as an adsorbent for mefenamic acid from water and found maximum adsorption of $16 \mathrm{mg} . \mathrm{g}^{-1}$ achieved at $47^{\circ} \mathrm{C}$ at $\mathrm{pH} 1.5$ (Majeed et al. 2017). For practical application of the removal process, it is necessary to optimize the various important factors using experimental design techniques.

The aim of this study is to apply a statistically based technique named the central composite design method to optimize the Fenton process for removal of mefenamic acid from aqueous solutions by varying the selected three main experimental variables such as concentration of oxidant $\mathrm{H}_{2} \mathrm{O}_{2}$, catalyst $\mathrm{Fe}^{2+}$, and $\mathrm{pH}$, and to develop a model to examine the single and combined effect of these variables on the removal process of the compound.

\section{MATERIALS AND METHODS}

\section{Materials}

Mefenamic acid $\left(\mathrm{C}_{15} \mathrm{H}_{15} \mathrm{NO}_{2}, 2\right.$-[(2,3dimethyl phenyl) amino] benzoic acid, 99\%, (Sigma -Aldrich, India), $\mathrm{H}_{2} \mathrm{O}_{2}$ $(30.0 \% \mathrm{w} / \mathrm{v})$, ferrous sulfate heptahydrate $\mathrm{FeSO}_{4} \cdot 7 \mathrm{H}_{2} \mathrm{O}$ (FS), $\mathrm{NaOH}, \mathrm{Na}_{2} \mathrm{~S}_{2} \mathrm{O}_{3}$ and sulphuric acid from Merk (India) were used as such without further purification. All chemicals used were of analytical grade unless indicated otherwise. HPLC grade acetonitrile (ACN), 98\% formic acid, and isopropanol (Merck) were used for the analysis.

\section{Experiments}

In a typical Fenton experiment, an aqueous solution of mefenamic acid having a concentration of $15 \mathrm{ppm}$ was prepared using Milli Q water and mixed with appropriate concentrations of $\mathrm{FeSO}_{4} \cdot 7 \mathrm{H}_{2} \mathrm{O}$ and $\mathrm{H}_{2} \mathrm{O}_{2}$ in liquid form in a $250 \mathrm{~mL}$ closed pyrex glass reactor. The reactor was placed in a dark chamber to avoid any photochemical reaction. The reaction volume was maintained as $100 \mathrm{~mL}$ and stirred continuously using a magnetic stirrer at $500 \mathrm{RPM}$. The $\mathrm{pH}$ of the sample was maintained by using $\mathrm{NaOH}$ and $\mathrm{H}_{2} \mathrm{SO}_{4}$ solutions as necessary. One drop of $0.1 \mathrm{~N}$ sodium sulfite solution was added to each sample taken to quench the action of any excess $\mathrm{H}_{2} \mathrm{O}_{2}$ present in the sample. All samples taken were filtered through $0.45 \mu \mathrm{m}$ syringe filters before the analysis. The removal of the compound was monitored by analyzing the initial samples and samples taken after $60 \mathrm{~min}$ of the interval by using HPLC.

\section{HPLC Analysis}

The quantitative determination of mefenamic acid was carried out with an HPLC-UV system on LC2030 plus liquid chromatograph (Shimadzu, Prominence $i$ ) equipped with a binary solvent gradient pump and an automatic injection system. The compounds were eluted off the C-18 column ( $250 \mathrm{~mm} \times 4.6 \mathrm{~mm}$ packed with $5 \mu \mathrm{m}$ particle size) with two solvents as mobile phases. The mobile phase consists of solvent A $0.1 \%$ formic acid in milliQ water and solvent B 100\% acetonitrile. The elution started at $0 \% \mathrm{~B}$ and was then linearly increased to $100 \% \mathrm{~B}$ over 10 minutes at a flow rate of $1.0 \mathrm{~mL} \cdot \mathrm{min}^{-1}$ then kept isocratic for 3 minutes and $\mathrm{B}$ concentration reached to initial level in the last $2 \mathrm{~min}$. The total run time of the gradient flow method was $15 \mathrm{~min}$. The injection volume was $20 \mu \mathrm{L}$ and the UV detection wavelength was at $275 \mathrm{~nm}$. The signal acquired from the detector was recorded by Lab Solution software.

\section{Experimental Design}

\section{Central Composite Design (CCD)}

The CCD was used to optimize the $\mathrm{pH}$, the concentration of $\mathrm{H}_{2} \mathrm{O}_{2}$ and $\mathrm{Fe}^{2+}$ and to evaluate the interaction among these three variables on the removal of Mefenamic acid. CCD is a very efficient design tool for fitting second-order models and optimizing the effective parameters with a minimum number of experimental runs (Bezerra et al. 2008). A CCD consists of cube points made up of design points from a $2^{\mathrm{k}}$ factorial or $2^{(\mathrm{k}-1)}$ fractional factorial design with $2 \mathrm{k}$ axial or "star" points, and $\mathrm{n}_{\mathrm{c}}$ center points (where $\mathrm{k}$ is the number of factors) (Im et al. 2012).

In this work, the $\mathrm{CCD}$ design consists of 8 cube points (all possible combinations of +1 and -1 for the 3 factors), 5 replicates of central points (coded as 0 for all 3 factors), and 6 axial points $(+1.68,-1.68$, and 0 for three factors). Thus there is a total of nineteen experiments with three factors coded at five levels.

A regression design is used to mathematically model the response as a function of the independent factors. The following general model equation is used to obtain the optimal response. 
$Y=\beta_{0}+\sum_{i=1}^{k} \beta_{i} X_{i}+\sum_{i=1}^{k} \beta_{i i} X_{i}^{2}+\sum_{i=1}^{k} \sum_{j=1}^{k} \beta_{i j} X_{i} X_{j}+\epsilon$

Where Y represents the response variable i.e., the percentage removal of the compound and ' $\mathrm{k}$ ' is the number of factors, $X_{i}$ to $X_{k}$ represents the independent variables, $\beta_{i}$ represents the regression coefficients for the linear or primary effect, $\beta_{i i}$ represents the quadratic coefficients or the squared effect, $\beta_{i j}$ represent the interaction effect coefficients and $\varepsilon$ is the random error (Chauhan et al. 2013).

In this study, three independent variables were considered and the quadratic polynomial equation for the response in terms of coded independent variables can be represented as

$$
\begin{aligned}
y= & \beta_{0}+\beta_{1} X_{1}+\beta_{2} X_{2}+\beta_{3} X_{3}+\beta_{11} X_{1}^{2}+\beta_{22} X_{2}^{2} \\
& +\beta_{33} X_{3}^{2}+\beta_{12} X_{1} X_{2}+\beta_{13} X_{1} X_{3}+\beta_{23} X_{2} X_{3} \ldots(2)
\end{aligned}
$$

MINITAB 16 was used to obtain the linear, squared, and interaction regression coefficients, and also the response surface and contour plots of the response model.

\section{RESULTS AND DISCUSSION}

Preliminary experiments were conducted by univariate method to fix the range of variables and the time interval for the process. The variables $\mathrm{X}_{1} \mathrm{X}_{2}$ and $\mathrm{X}_{3}$ were the concentration of added $\mathrm{H}_{2} \mathrm{O}_{2}, \mathrm{Fe}^{2+}$ and the $\mathrm{pH}$ maintained at the start of

Table 1: Experimental range and levels of selected independent factors.

\begin{tabular}{|lllll|}
\hline \multicolumn{1}{|c|}{ Independent factors } & & Range and Levels \\
\hline & $-\alpha$ & -1 & 0 & 1 \\
\hline $\begin{array}{l}\mathrm{H}_{2} \mathrm{O}_{2} \text { concentration }(\mathrm{mM}) \\
\left(\mathrm{X}_{1}\right)\end{array}$ & 2.64 & 4 & 6 & 8 \\
$\mathrm{Fe}^{2+}$ concentration (mM) & & & 9.36 \\
$\left(\mathrm{X}_{2}\right)$ & $6.4 \times 10^{-3}$ & $2.0 \times 10^{-2}$ & $4.0 \times 10^{-2}$ & $6.00 \times 10^{-2}$ \\
$\mathrm{pH}$ & & & 9 & $9.36 \times 10^{-2}$ \\
$\left(\mathrm{X}_{3}\right)$ & 0.96 & 3 & 6 & 11.04 \\
\hline
\end{tabular}

\begin{tabular}{|c|c|c|c|c|c|}
\hline \multirow[t]{2}{*}{ Run } & \multicolumn{3}{|c|}{ Coded variables } & \multicolumn{2}{|c|}{$\%$ Removal of Mefenamic acid } \\
\hline & $\mathrm{X}_{1}$ & $\mathrm{X}_{2}$ & $\mathrm{X}_{3}$ & Observed values & Predicted values \\
\hline 1 & 0.00 & -1.68 & 0.00 & 27.31 & 29.38 \\
\hline 2 & -1.00 & -1.00 & -1.00 & 58.65 & 56.32 \\
\hline 3 & 0.00 & 0.00 & 0.00 & 60.65 & 60.54 \\
\hline 4 & 1.00 & -1.00 & -1.00 & 61.43 & 59.16 \\
\hline 5 & -1.00 & 1.00 & -1.00 & 52.75 & 51.66 \\
\hline 6 & -1.00 & 1.00 & 1.00 & 22.70 & 23.82 \\
\hline 7 & -1.68 & 0.00 & 0.00 & 36.43 & 37.09 \\
\hline 8 & 1.68 & 0.00 & 0.00 & 64.50 & 65.47 \\
\hline 9 & 0.00 & 0.00 & 0.00 & 60.80 & 60.54 \\
\hline 10 & 0.00 & 0.00 & 0.00 & 60.46 & 60.54 \\
\hline 11 & 0.00 & 0.00 & 1.68 & 23.41 & 21.38 \\
\hline 12 & 1.00 & 1.00 & 1.00 & 53.57 & 54.75 \\
\hline 13 & -1.00 & -1.00 & 1.00 & 16.84 & 17.09 \\
\hline 14 & 0.00 & 0.00 & 0.00 & 60.52 & 60.54 \\
\hline 15 & 0.00 & 0.00 & -1.68 & 70.82 & 74.49 \\
\hline 16 & 1.00 & 1.00 & -1.00 & 80.16 & 78.75 \\
\hline 17 & 0.00 & 0.00 & 0.00 & 60.54 & 60.54 \\
\hline 18 & 1.00 & -1.00 & 1.00 & 23.85 & 23.78 \\
\hline 19 & 0.00 & 1.68 & 0.00 & 51.92 & 51.48 \\
\hline
\end{tabular}

Table 2: CCD matrix in terms of coded units along with the observed and predicted removal values of the compound after 1 hour Fenton process. 
the reaction. The range of variables $\mathrm{H}_{2} \mathrm{O}_{2}(4-8 \mathrm{mM}), \mathrm{Fe}^{2+}$ (2 $\times 10^{-2}-6 \times 10^{-2} \mathrm{mM}$ ), and $\mathrm{pH}$ ( 3 to 9 ) was fixed based on preliminary studies and the five different levels of each variable were selected based on the central composite design. Table 1 shows the various levels of selected independent factors and Table 2 is the list of coded variables and the observed and predicted removal values of the response.

The model equation obtained for the removal of mefenamic acid in terms of coded variables was as follows:

$$
\begin{aligned}
& Y=60.536+8.445 X_{1}+6.578 X_{2}-15.807 X_{3}- \\
& 3.279 X_{1}{ }^{2}-7.123 X_{2}{ }^{2}-4.466 X_{3}{ }^{2}+6.061 X_{1} X_{2}+ \\
& 0.961 X_{1} X_{3}+2.843 X_{2} X_{3}
\end{aligned}
$$

Where: $\mathrm{Y}$ is the percentage removal of mefenamic acid and $\mathrm{X}_{1}$ and $\mathrm{X}_{2}$ were the initial concentration of $\mathrm{H}_{2} \mathrm{O}_{2}$ and $\mathrm{Fe}^{2+}$ in $\mathrm{mM}$ and $\mathrm{X}_{3}$ is the initial $\mathrm{pH}$ value.

\section{Statistical Analysis}

The quality of the proposed model was checked by the coefficient of determination $\left(R^{2}\right)$ and adjusted $R^{2}$. The coefficient of determination $\left(\mathrm{R}^{2}\right)$ indicates the proportion of variation in the response described by the model. If the value of $\mathrm{R}^{2}$ is closer to 1 , it indicates that the model is good to describe the variation in response as a function of independent variables (Ishak \& Malakahmad 2013). Adjusted $\mathrm{R}^{2}$ is another useful statistical tool to evaluate the model adequacy; it is a modified $R^{2}$ value by taking into account the number of covariates or predictors in the model. The ' $F$ value' was the ratio of the mean sum of square due to the model variance and error variance, and is used to test the null hypothesis (Chauhan et al. 2013). The statistical significance was assessed by the lack of fit test. The result of the analysis of variance (ANOVA) was presented in Table 3.

The ANOVA result shows that the linear, quadratic, and interaction terms are significant since the corresponding $\mathrm{p}$-values are $<0.05$. A high $\mathrm{R}^{2}$ value of 0.9936 and an adjusted $R^{2}$ value of 0.9873 indicates the significance of the model and its adequacy to predict the response. A normal probability plot of residuals versus response is shown in Fig. 1. The normal probability plot is a graphical method for determining residuals' normality. Fig. 1 shows that the points are close to the straight line and the model is sufficient to describe the response.

Table 3: ANOVA result of the quadratic model for percentage removal of Mefenamic acid.

\begin{tabular}{|lllllll|}
\hline Source & Sum of squares & Df & Square mean & F value & P value \\
\hline Regression & 6238.4 & 9 & 693.16 & 156.08 & 0.000 & Remarks \\
Linear & 4972.64 & 3 & 1657.55 & 373.23 & 0.000 \\
Square & 899.77 & 3 & 299.92 & 67.53 & 0.000 & 0.000 \\
Interaction & Residual & 366.00 & 3 & 122.00 & 27.47 & \\
Error & 39.97 & 9 & 4.44 & & \\
Lack-of-Fit & 39.90 & 5 & 0.02 & & \\
Pure Error & 0.07 & 4 & & & & \\
Total & 6278.37 & 18 & & & & \\
\hline
\end{tabular}

$\mathrm{R}^{2}=0.9936, \mathrm{R}^{2}$ (adjusted) $=0.9873$

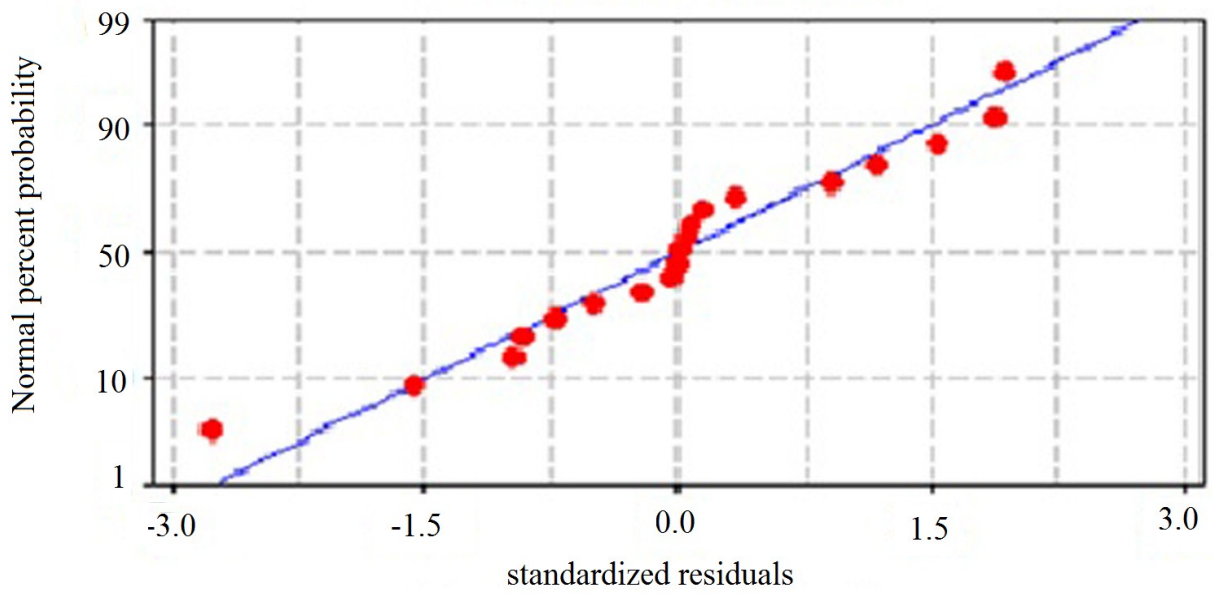

Fig. 1: Normal Probability Plot, \% removal of mefenamic acid. 


\section{Effect of Independent Variables on the Removal of the Compound}

The plot in Fig. 2. shows the effect of independent variables $\mathrm{H}_{2} \mathrm{O}_{2}, \mathrm{Fe}^{2+}$ and $\mathrm{pH}$ on the mean removal of mefenamic acid in 19 experiments conducted based on the central composite design. Fig. 2 shows a sharp increase in the average removal value from 4 to $9.36 \mathrm{mM}$ concentration of $\mathrm{H}_{2} \mathrm{O}_{2}$. This may be due to the more $\bullet \mathrm{OH}$ radicals produced during the more concentration of $\mathrm{H}_{2} \mathrm{O}_{2}$ and thus enhancing the removal of the compound (Rezaee et al. 2014). The second curve shows that the mean removal value of mefenamic acid increases up to $55 \%$ when the iron concentration changes from 0.0064 to 0.040. Further increase in iron concentration did not show an increase in the removal efficiency. This shows that a high concentration of metal ions was not favoring the removal of this compound. This may be due to the ferrous ion inhibition that occurs at a high concentration of $\mathrm{Fe}^{2+}$ in the system. The excess metal ion increases the yield of $\mathrm{Fe}^{2+}$ ions which act as a scavenger by quenching the hydroxyl ions formed (Wang et al. 2014). The higher concentration of $\mathrm{Fe}^{2+}$ in the system can also result in the production of hydroperoxyl radical $(\bullet \mathrm{HO})$ which has less oxidation potential than hydroxyl radicals (Karale et al. 2014). Effect of $\mathrm{pH}$ indicates that the mean removal of mefenamic acid was more favorable at the acidic $\mathrm{pH}$ range than at alkaline $\mathrm{pH}$. Mefenamic acid shows more than $50 \%$ average removal efficiency in neutral $\mathrm{pH}$ but the removal was less than $30 \%$ in alkaline $\mathrm{pH}$.

\section{Combined Effect Among the Independent Variables on the Removal Efficiency}

To understand the interaction effect among the independent variable, contour plots and $3 \mathrm{D}$ response surface curves were considered. Fig. 3. shows the profile for the quadratic response surface and the contour plots of \% removal of mefenamic acid versus various coded independent variables.

From the contour plot Fig. 3(a), it was evident that more than $70 \%$ removal of mefenamic acid was obtained at a higher concentration of added $\mathrm{H}_{2} \mathrm{O}_{2}$ and $\mathrm{Fe}^{2+}$ at a neutral $\mathrm{pH}$ range. Fig. 3(b) indicates that a removal value above $60 \%$ was obtained at medium concentration levels of $\mathrm{H}_{2} \mathrm{O}_{2}$ with varying $\mathrm{Fe}^{2+}$ concentrations in the acidic $\mathrm{pH}$ range of the solution. Interaction between $\mathrm{pH}$ and $\mathrm{H}_{2} \mathrm{O}_{2}$ at medium $\mathrm{Fe}^{2+}$ concentration was shown in Fig. 3(c). It shows that removal of mefenamic acid was more than $75 \%$ at medium to high levels of $\mathrm{H}_{2} \mathrm{O}_{2}$ concentration in acidic $\mathrm{pH}$ values. This was due to more production of $\bullet \mathrm{OH}$ radicals from added oxidants resulting in the degradation of the compound (Im et al. 2012).

\section{Optimization of Operating Parameters}

The optimal value of the independent variable for maximizing the response was obtained by using the Minitab Response optimizer. The value of the process variable obtained corresponding to the optimum response is presented in Table 4. Accordingly, the maximum removal of $82.36 \%$ for the mefenamic acid was obtained at optimum conditions of $9.36 \mathrm{mM}$ of $\mathrm{H}_{2} \mathrm{O}_{2}, 0.058 \mathrm{mM} \mathrm{Fe}^{2+}$ and at a $\mathrm{pH}$ of 2.08 . The experimental test was conducted in triplet using the predicted value of independent variables and it shows that the average experimentally observed removal value of $81.24 \%$ is very close to the predicted value using the model. It implies that the RSM is a good tool for optimizing the operating parameters in this Fenton process for the removal of mefenamic acid.

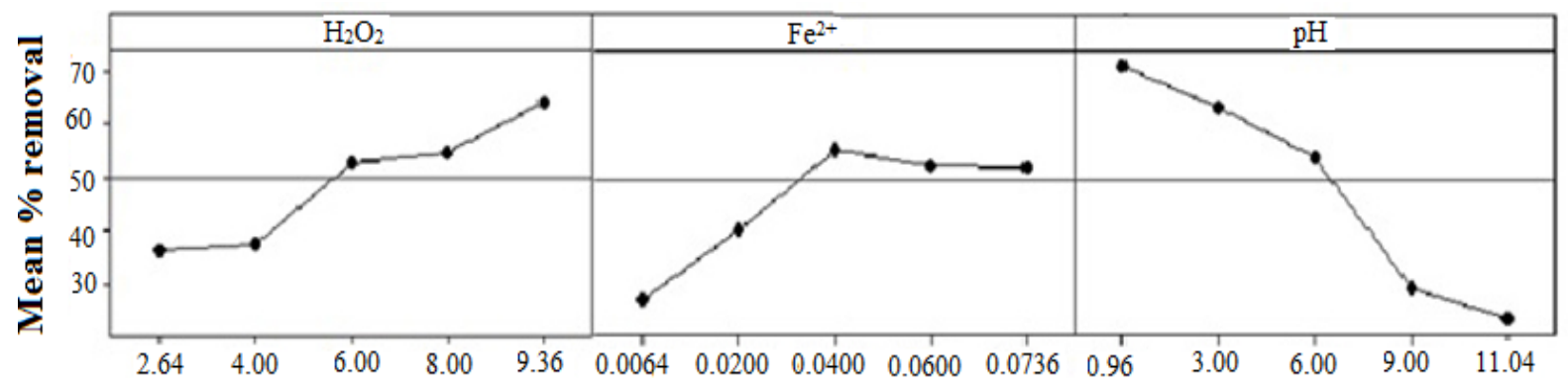

Fig. 2: Primary effect of independent variables $\mathrm{H}_{2} \mathrm{O}_{2}, \mathrm{Fe}^{2+}$ and $\mathrm{pH}$ on the removal of mefenamic acid.

Table 4: Optimum value of process variables for maximum removal of Mefenamic acid and its predicted and observed values.

\begin{tabular}{|llllll|}
\hline Response & $\begin{array}{l}\mathrm{H}_{2} \mathrm{O}_{2} \\
(\mathrm{mM})\end{array}$ & $\begin{array}{l}\mathrm{Fe}^{2+} \\
(\mathrm{mM})\end{array}$ & $\mathrm{pH}$ & $\begin{array}{l}\text { Predicted Removal } \\
(\%)\end{array}$ & $\begin{array}{l}\text { Observed Removal } \\
(\%)\end{array}$ \\
\hline $\begin{array}{l}\text { Removal of } \\
\text { Mefenamic acid }\end{array}$ & 9.36 & 0.058 & 2.1 & 82.36 & 81.24 \\
\hline
\end{tabular}



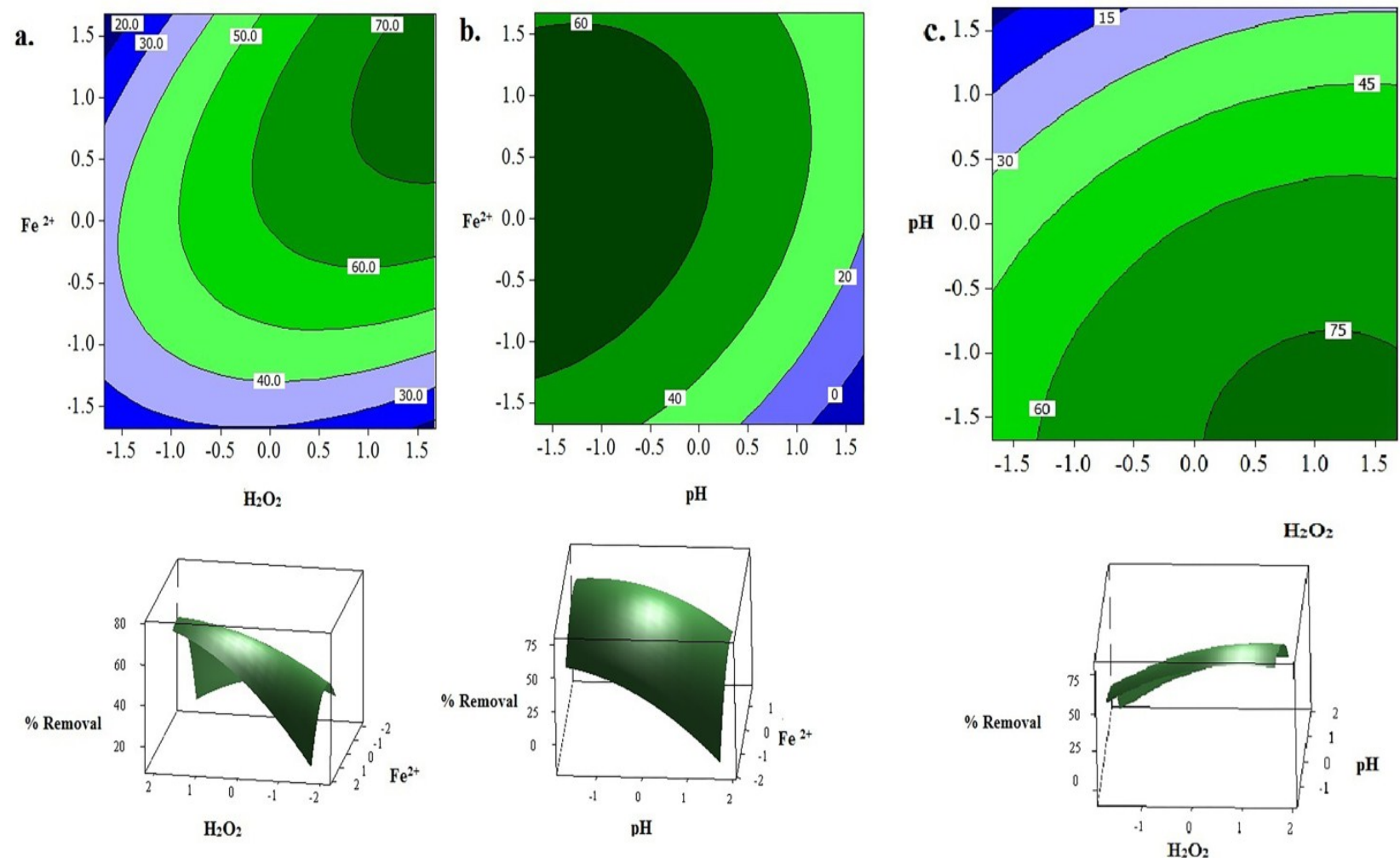

Fig. 3: Contour plots and Response surface plots for mefenamic acid removal versus coded independent variables a) $\mathrm{H}_{2} \mathrm{O}_{2}$ with $\mathrm{Fe}{ }^{2+}$ b) $\mathrm{pH}$ with $\mathrm{Fe}^{2+}$ and c) $\mathrm{H}_{2} \mathrm{O}_{2}$ with $\mathrm{pH}$.

\section{CONCLUSION}

In this work, RSM was used to optimize the removal of mefenamic acid by using the Fenton process. By using the central composite method, three main operating parameters in the Fenton process including the $\mathrm{pH}$, the initial $\mathrm{H}_{2} \mathrm{O}_{2}$, and $\mathrm{Fe}$ ${ }^{2+}$ concentration were examined. Based on the experimental results and the relationship between the selected independent variables, a quadratic model was obtained. Statistical test by ANOVA showed a high coefficient of determination value $\left(R^{2}=0.9936\right)$ which indicates a good agreement of the model with experimental data. The interaction effect of experimental parameters on the response was established by response surface curves and contour plots. A high percentage removal value of $82.36 \%$ was obtained under the optimal value of variables in the process. Further confirmation experiment under the optimized condition results in a maximum removal value of $81.24 \%$. This indicates that the model is in accordance with the experimental data. Our study implies that RSM based on the central composite method is a useful tool for optimizing the operating parameters for the Fenton removal process of mefenamic acid.

\section{ACKNOWLEDGMENT}

The authors are thankful to Kerala State Council for Science, Technology, and Environment for the financial support extended to this research work.

\section{REFERENCES}

Andreozzi, R., Caprio,V., Insola, A. and Marotta, R. 1999. Advanced oxidation processes for water purification and recovery, Cataly. Today., 53: 51-53.

Bezerraa, M.A., Santelli, R.E., Oliveiraa, E.P., Villara, L.S. and Escaleiraa, L.A. 2008. Response surface methodology ( RSM ) as a tool for optimization in analytical chemistry. Talanta, 76: 965-977.

Bu, Q., Shi, X., Yu, G., Huang, J. and Wang, B. 2016. Assessing the persistence of pharmaceuticals in the aquatic environment: challenges and needs. Emerg. Contam., 2(3): 145-147.

Chang, E.E., Liu, T.Y., Huang, C.P., Liang, C.H. and Chiang, P.C. 2012. Degradation of mefenamic acid from aqueous solutions by the ozonation and $\mathrm{O}_{3} / \mathrm{UV}$ processes. Sep. Purif. Technol., 98: 123-129.

Chauhan, V.S., Bhardwaj, N.K. and Chakrabarti, K.S. 2013. Application of response surface methodology and central composite design for the optimization of talc filler and retention aid in papermaking. Indian $\mathrm{J}$. Chem. Technol., 20(2): 121-127.

Chen, P., Wang, F.L., Yao, K., Ma, J.S., Li, F.H., Lv, W.Y. and Liu, G.G. 2016. Photodegradation of mefenamic acid in aqueous media: kinetics, 
toxicity and photolysis products. Bull. Environ. Contam. Toxicol., 96(2): 203-209.

Colombo, R., Ferreira, T.C.R., Ferreira, R.A. and Lanza, M.R.V. 2016. Removal of mefenamic acid from aqueous solutions by oxidative process: optimization through experimental design and HPLC/UV analysis. J. Environ. Manage., 167: 206-213.

Deng, Y. and Zhao, R. 2015. Advanced oxidation processes (AOPS) in wastewater treatment. Curr. Pollut. Rep., 1: 167-176.

Gimeno, O., Rivas, J., Encinas, A. and Beltran, F. 2010. International application of advanced oxidation processes to mefenamic acid elimination. Int. J.Chem. Mol. Nuc. Mater. Metall. Eng., 4(6): 399-401.

Idrees, U. 2015. Estimation and analysis of mefenamic acid suspension; a proportional investigation. SOJ Pharm. Pharm. Sci., 3(2): $2-4$.

Im, J.K., Cho, I.H., Kim, S.K. and Zoh, K.D. 2012. Optimization of carbamazepine removal in $\mathrm{O} 3 / \mathrm{UV} / \mathrm{H} 2 \mathrm{O} 2$ system using a response surface methodology with central composite design. Desalination, 285: 306-314.

Ishak, S. and Malakahmad, A. 2013. Optimization of Fenton process for refinery wastewater biodegradability augmentation. Korean J. Chem. Eng., 30(5): 1083-1090.

Karale, S.R., Manu, B. and Shrihari, S. 2014. Fenton and photo-Fenton oxidation processes for degradation of 3-aminopyridine from water. APCBEE Procedia, 9: 25-29.
Majeed, B.A.A., Muhseen, R.J. and Jassim, N.J. 2017. Adsorption of mefenamic acid from water by bentonite poly urea-formaldehyde composite adsorbent. J. Eng., 23(7): 50-73.

Naveed, S., Qamar, F., Abbas, S.S., Safdar, S., Ameer, S., Matavos-Aramyan, S. and Moussavi, M. 2017. Advances in Fenton and Fenton-based oxidation processes for industrial effluent contaminants control-A review. Int. J. Environ. Sci. Nat. Resour., 2(4): 1-18.

Oturan, M.A. and Aaron, J.J. 2014. Advanced oxidation processes in water/ wastewater treatment: principles and applications. A review. Crit. Rev. Environ. Sci. Technol., 44(23): 2577-2641.

Rezaee, R., Maleki, A., Jafari, A., Mazloomi, S., Zandsalimi, Y. and Mahvi, A.H. 2014. Application of response surface methodology for optimization of natural organic matter degradation by the advanced oxidation process. J. Environ. Health Sci. Eng., 12(67): 1-8.

Rivera-Utrilla,J., Sánchez-Polo,M., Ferro-García, M, A., Prados-Joya,G.and Ocampo-Pérez, R. 2013. Pharmaceuticals as emerging contaminants and their removal from water. A review. Chemosphere, 93(7): 12681287.

Roudi, M.A., Chelliapan, S., Mohtar, W.H.M.W. and Kamyab, H. 2018. Optimization of the fenton process for the treatment of landfill leachate using an artificial neural network. Water, 10(595): 1-12.

Wang, C., Zhang, S., Zhang, Z., Zeng, M. and Yuji, S. 2014. Optimization and interpretation of Fenton and UV/Fenton processes for degradation of syringyl lignin. J. Environ. Anal. Chem., 01(02): 2-6. 